\title{
Delphi developed syllabus for the medical specialty of sport and exercise medicine: part 2
}

\author{
David Humphries (D) , ${ }^{1,2}$ Rod Jaques, ${ }^{3,4} \mathrm{H}$ Paul Dijkstra (D) , 5 Irfan Asif (D) , \\ Mark E Batt, ${ }^{4,8}$ Mats Borjesson (D) , ${ }^{9}$ Emin Ergen, ${ }^{10}$ Celeste Geertsema (D) , 10 \\ Boris Gojanovic (D) , ${ }^{11}$ Anca lonescu, ${ }^{12}$ Dina Christina Janse van Rensburg (D) , 13 \\ Constance Lebrun, ${ }^{14}$ Nahar Azmi Mohamed, ${ }^{15}$ Margo Mountjoy (D) , 16,17 \\ Tvisha Parikh, ${ }^{18}$ Diana Robinson, ${ }^{19}$ Robert Sallis, ${ }^{20}$ Martin Schwellnus (D) , ${ }^{21}$ \\ Padraig Sheeran ${ }^{22}$
}

- Additional material is published online only. To view, please visit the journal online (http://dx.doi.org/10.1136/ bjsports-2020-102102).

For numbered affiliations see end of article.

\section{Correspondence to}

Dr David Humphries, School of Medicine, University of Tasmania Faculty of Health, Hobart 7000, Tasmania, Australia; sportsmedicine@outlook.com. au

Accepted 7 September 2020 Published Online First 24 September 2020

\section{ABSTRACT}

Training in the medical specialty of sport and exercise medicine (SEM) is available in many, but not all countries. In 2015, an independent Delphi group, the International Syllabus in Sport and Exercise Medicine Group (ISSEMG), was formed to create a basic syllabus for this medical specialty. The group provided the first part of this syllabus, by identifying 11 domains and a total of 80 general learning areas for the specialty, in December 2017. The next step in this process, and the aim of this paper was to determine the specific learning areas for each of the 80 general learning areas. A group of 26 physicians with a range of primary medical specialty qualifications including, Sport and Exercise Medicine, Family Medicine, Internal Medicine, Cardiology, Rheumatology and Anaesthetics were invited to participate in a multiple round online Delphi study to develop specific learning areas for each of the previously published general learning areas. All invitees have extensive clinical experience in the broader sports medicine field, and in one or more components of sports medicine governance at national and/or international level. SEM, Family Medicine, Internal Medicine, Cardiology, Rheumatology and Anaesthetics were invited to participate in a multiple round online Delphi study to develop specific learning areas for each of the previously published general learning areas. All invitees have extensive clinical experience in the broader sports medicine field, and in one or more components of sports medicine governance at national and/or international level. The hierarchical syllabus developed by the ISSEMG provides a useful resource in the planning, development and delivery of specialist training programmes in the medical specialty of SEM.

\section{INTRODUCTION}

The purpose of the International Syllabus in Sport and Exercise Medicine Group (ISSEMG) has been detailed in the initial paper. ${ }^{1}$ Briefly, it was determined that, while there was a need to increase the numbers of sport and exercise medicine (SEM) physicians internationally, there were potential barriers to the development of SEM training in countries without training programmes, one of which was the requirement to develop a syllabus. The creation of a basic international syllabus for the medical specialty of SEM was seen as a solution to that barrier, and the ISSEMG has undertaken the development of this syllabus. Of note, WHO has issued a global action plan on physical activity, ${ }^{2}$ the recommendations of which can only emphasise the need for more SEM specialists. The aim of this international Delphi consensus was to agree on the specific learning areas for each of the 80 previously agreed general learning areas of the 11 domains in the medical specialty of SEM. There has been no change in the purpose, focus or funding of the project since the first publication.

\section{METHODS}

As detailed in the initial paper, ${ }^{1}$ the ISSEMG decided on a hierarchical syllabus structure, comprising broad domains of learning, for example, the domain 'Physical activity and human health'. Each domain was broken into general learning areas, for example, in the physical activity and human health domain 'Applied exercise physiology: types of exercise, effects of exercise and maximising adaptations to exercise and 'Physical activity guidelines and recommendations' are among the general learning areas. This publication details the third level of the hierarchy, namely the specific learning areas under each general learning areas. The project has continued to use a modified Delphi process. The members of the Delphi group were invited to be part of this process on the basis that they had significant skills in one or more of the following: SEM syllabus and/or curriculum development, SEM training programme development and/ or implementation, and SEM specialist assessment programme development and/or implementation. Four additional members (EE, CG, AI and CL) were added to the group involved in the original paper to broaden representation, and one member of the original team was replaced by two others late in the process because of a scheduled academic hand over. For each set of specific learning areas an initial questionnaire, a commentary and 1-2 follow-up questionnaires have been used to determine which specific learning areas would be included in the syllabus. When required email discussions initiated by group members assisted the process. A total of 24 questionnaires were used in the development of the specific learning areas. The response rates to questionnaires varied between 55\% and $100 \%$, with the overall average response rate being $65 \%$. A cut point of $80 \%$ agreement among the respondents to each questionnaire was used to 
indicate group agreement for inclusion in all but four cases. In these cases, as indicated in the specific learning areas list with an asterisk, $79 \%$ was accepted. The lack of $100 \%$ response rate was recognised as a potential weakness in the methodology. This was, in part, addressed by the fact that all members of the group were made aware of the results of the initial round scores for each topic as part of the follow-up commentary. All members of the group were able to provide additional commentary at that point and were able to respond to follow-up questionnaires on the same topic.

\section{Results}

The domain, general and specific learning areas for the SEM specialty syllabus are presented in a numbered tabular form for ease of use and cross-referencing (online supplemental file 1).

Each specific learning area represents an area of medical knowledge determined by the ISSEMG to be fundamental to medical specialists in the specialty of SEM. Some are relatively broad areas of knowledge, some quite specific. The ISSEMG also added specific learning areas to the previously uncategorised 'Advanced skills' group. These are learning areas which may be regarded as advanced learning in the specialty, pertinent to some but possibly not all national medical organisations seeking to train in the specialty. These are now listed in the 'Extrinsic skills of an SEM physician' domain. Each Domain, General learning area and Specific learning area has been listed in a numerical structure to assist with understanding the overall syllabus and to allow easy referencing. Additional comments, agreed by the ISSEMG, have been added in some sections to enhance the document. In a number of instances, there have been minor adjustments to the titles and numbering of the general learning areas in this paper compared with the original paper. ${ }^{1}$ These have been made to assist with the clarity and utility of the syllabus. These changes are noted where they have occurred.

\section{DISCUSSION}

Specialty training in SEM is evolving, and various training models exist. The ISSEMG syllabus can be adapted to a variety of contexts, including training systems where SEM specialisation is gained as an additional component of a primary specialty. In such circumstances, components of the syllabus may have already been covered during training in the primary specialty. The breadth and depth of the syllabus presented is substantial and it should be evident that the training of specialist SEM physicians requires significant resources and time. The ISSEMG recognises that some of the specific learning areas listed cover areas that are still in flux in terms of our level of knowledge. As such the ISSEMG syllabus should be treated as a living document by national medical organisations that guide training in the medical specialty of SEM. They will need to refine and adapt the syllabus to their needs and consider evolving knowledge.

Developing a medical specialty curriculum from a syllabus is a significant undertaking. Curriculum developers must have a deep understanding of the relevant national (or local) medical system and available resources, the health priorities of the given system, the medical pregraduate and postgraduate education processes available in that system, and the proposed scope of practice of the new specialty. For the actual development of a curriculum several other fundamentals are required. These include: (1) a curriculum document, based on a syllabus, that clearly details the relevant learning outcomes required to cover the learning areas of the syllabus, (2) teaching and learning methods designed specifically to satisfy the requirements of each learning area, mapped to the curriculum, (3) validated formative and summative assessment processes blueprinted to the curriculum document, (4) a comprehensive outline of the training process, which in SEM typically includes items such as the usual training duration required, necessary clinical exposure, sports team and event coverage, research and the reporting requirements of trainees and supervisors, (5) access to suitable training instructors and training positions, (6) the ability to develop doctors who are not just medical experts but also have competence in other fundamentals including, but not limited to communication, collaboration, scholarship, leadership and health advocacy and (7) a cycle of review and renewal of the curriculum.

\section{CONCLUSION}

The ISSEMG has developed a syllabus for the medical specialty of SEM. This syllabus will be of value to national medical organisations developing SEM specialty or subspecialty training programmes and may inform benchmarking of current training programmes. This syllabus will contribute to the future international development of the medical specialty of SEM internationally. No further publications are planned by the ISSEMG.

\section{Author affiliations}

${ }^{1}$ School of Medicine, University of Tasmania Faculty of Health, Hobart, Tasmania, Australia

${ }^{2}$ Past President, Australasian College of Sport and Exercise Physicians, Melbourne, Victoria, Australia

${ }^{3}$ Sports Medicine, English Institute of Sport, London, UK

${ }^{4}$ Past President, Faculty of Sport And Exercise Medicine, Edinburgh, UK

${ }^{5}$ Medical Education, Aspetar Qatar Orthopaedic and Sports Medicine Hospital, Doha, Ad Dawhah, Qatar

${ }^{6}$ Department for Continuing Education, University of Oxford, Oxford, UK

${ }^{7}$ Department of Family and Community Medicine, UAB, Birmingham, Alabama, USA

${ }^{8}$ Centre for Sport, Exercise \& Osteoarthritis Research Versus Arthritis, Nottingham

University Hospitals NHS Trust, Nottingham, UK

${ }^{9}$ Center for Health and Performance, Goteborgs universitet Sahlgrenska Akademin,

Goteborg, Sweden

${ }^{10}$ Sports Medicine, Aspetar Orthopaedic and Sports Medicine Hospital, Doha, Ad

Dawhah, Qatar

${ }^{11}$ Sports Medicine, Swiss Olympic Medical Center, Hopital de la Tour, Meyrin, Geneva,

Switzerland

${ }^{12}$ Sports Medicine, Carol Davila University of Medicine and Pharmacy, Bucharest, Bucuresti, Romania

${ }^{13}$ Sport Exercise Medicine and Lifestyle Institute \& Section Sports Medicine, University of Pretoria Faculty of Health Sciences, Pretoria, South Africa

${ }^{14}$ Department of Family Medicine, University of Alberta Faculty of Medicine and Dentistry, Edmonton, Alberta, Canada

${ }^{15}$ Sports Medicine, University of Malaya Medical Centre, Kuala Lumpur, Wilayah Persekutuan, Malaysia

${ }^{16}$ Family Medicine, McMaster University Michael G DeGroote School of Medicine, Waterloo, Ontario, Canada

${ }^{17}$ Bureau, FINA, Lausanne, Switzerland

${ }^{18}$ Sports Medicine, Sir HN Reliance Foundation Hospital and Research Centre, Mumbai, Maharashtra, India

${ }^{19}$ Chair of Curriculum Committee, Australasian College of Sport and Exercise Physicians, Melbourne, Victoria, Australia

${ }^{20}$ Family Medicine, Kaiser Permanente Medical Center, Fontana, California, USA

${ }^{21}$ Sport, Exercise Medicine and Lifestyle Institute, University of Pretoria Faculty of

Health Sciences, Pretoria, South Africa

${ }_{22}$ Past Dean, Royal College of Surgeons in Ireland Faculty of Sports and Exercise Medicine, Dublin, Ireland

Twitter H Paul Dijkstra @DrPaulDijkstra, Boris Gojanovic @drsportsante and Margo Mountjoy@margo.mountjoy

Collaborators Delphi group members: FJG Backx; Bert Fields; Maarten Koornneef; Els Stolk.

Contributors All listed authors have made substantial contributions to the conception or design of the work, or the acquisition, analysis or interpretation of data. Additionally they have been involved in the drafting or critical review and have approved the final version.

Funding The authors have not declared a specific grant for this research from any funding agency in the public, commercial or not-for-profit sectors. 
Competing interests None declared.

Patient consent for publication Not required.

Provenance and peer review Not commissioned; externally peer reviewed.

Data availability statement All data relevant to the study are included in the article

\section{ORCID iDs}

David Humphries http://orcid.org/0000-0003-3171-0243

H Paul Dijkstra http://orcid.org/0000-0003-3166-1357

Irfan Asif http://orcid.org/0000-0003-0655-6264

Mats Borjesson http://orcid.org/0000-0001-6502-8838
Celeste Geertsema http://orcid.org/0000-0001-5439-7451

Boris Gojanovic http://orcid.org/0000-0001-5075-9371

Dina Christina Janse van Rensburg http://orcid.org/0000-0003-1058-6992

Margo Mountjoy http://orcid.org/0000-0001-8604-2014

Martin Schwellnus http://orcid.org/0000-0003-3647-0429

\section{REFERENCES}

1 Humphries D, Jaques R, Dijkstra HP, et al. A Delphi developed syllabus for the medical specialty of sport and exercise medicine. Br J Sports Med 2018;52:490-2.

2 WHO. Global action plan on physical activity 2018-2030: more active people for a healthier world. Geneva, 2018. 